\title{
The Health Care Ethics: Overview of the Basics
}

\author{
Ahmed Bait Amer \\ Sultan Qaboose University Hospital, Muscat, Oman \\ Email: ahmedsaid-777@hotmail.com
}

How to cite this paper: Amer, A.B. (2019) The Health Care Ethics: Overview of the Basics. Open Journal of Nursing, 9, 183-187. https://doi.org/10.4236/ojn.2019.92017

Received: January 14, 2019

Accepted: February 22, 2019

Published: February 25, 2019

Copyright $\odot 2019$ by author(s) and Scientific Research Publishing Inc. This work is licensed under the Creative Commons Attribution International License (CC BY 4.0).

http://creativecommons.org/licenses/by/4.0/

\begin{abstract}
In this overview we answers certain Questions in order to increase the awareness towards the basic of the health care ethics: what is ethics, what are the several fields of ethics connected to medical activities, what are the types of Ethical approaches in relation to the medical practice. Conclusion: Through understanding the basics of the ethics, the awareness of the medical ethics in the health care can be increased.
\end{abstract}

\section{Keywords}

Ethics, Medical Ethics, Normative, Non Normative

\section{Introduction}

Medicine and health care deal with human health, life, and death, and medical ethics deals with ethical norms for the practice of medicine and health care or how it ought to be done so the concerns of medical ethics are among the most important and consequential in human life [1]. Physicians and nurses commonly encounter ethical and legal issues in their work place; however many of these professionals are either unaware of their importance or unable to appropriately deal with these issues [2] remarkably. Few clinicians are interested in bioethics or moral philosophy. One explanation for this is that bioethics is often perceived by clinicians as something strange, useless, and even provocative: ethicists are regarded as people who don't know anything about the real world, who don't care that they know so little, who produce literature that is difficult to relate to and understand, and whose advices are of little use in clinical practice. This perception is a reason why clinicians often turn their backs on the field of medical ethics [3]. For such reasons the importance of an ethical basis for medical practice has been emphasized in recent years [4] [5]. Ethics now has become to mean "a set of rules or standards governing the conduct of a person or the members of a profession". Medical ethics deals with the moral principles that medics should 
follow in their professional life. The scope of medical ethics is wide and inclusive of developing codes and guidelines, promoting ethical practices and preventing ethical breaches. It also includes the physicians' relationship with patients, colleagues, members of the related industry, and at large, the society and the nation or the state [6]. The lack of perception and awareness among health care professionals highlights the significance of discussing basics of health care ethics.

\section{Overview of the Ethics in Health Care}

Health care ethics are important for each person who provides some aspect of health care, from the custodian who cleans a clinic's office to the head of surgery at the most prestigious medical facilities, everyone who provides some aspect of health care needs to understand the ethical responsibilities and limits. Likewise, each person who interacts with health care, from a single blood draw at a store front lab to major surgery in an large city medical center, needs to understand his or her responsibilities and rights in regards to heath car ethics [7], in attempts of answering the following questions to educate the health care professionals on the basics of health care ethics.

\section{The First Question We Have to Answer Is What Is Ethics?}

Ethics has a long history in Western philosophy. The word "ethics" comes from the Greek word Ethika, which is an adjective that itself derives from èthos, the Greek word for character. For Aristotle, character is of central importance to ethics, and one cannot have a good character without having formed good ethoi or habits. So ethics is Greek for customs, and morality comes from mores, which is Latin for customs [8] [9].

\subsection{What Then, Is Ethics?}

Ethics is a branch of philosophy that seeks to determine how human actions may be judged right or wrong. When the study of the ethics is applied to a professional field, it becomes necessary to discuss not only basic ethical positions, but also the nature of the profession and the conditions under which that profession operates [10]. Ethics also, is understood as a philosophical study of morality [11]; morality refers to human conduct and values whereas ethics refers to the study of those. The two terms are used interchangeably however, morals may be perceived as prescriptions or rules to guide our actions and behavior whereas ethics may be perceived as a set of analytical tools or a process that helps to identify right conduct and determine appropriate behavior. In one sense morality is what we ideally aim for whereas ethics is a process that has a theoretical reflective and normative element that helps to achieve the aim. In other words the use of moral or ethical theory can be applied to help resolve dilemmas [12].

\subsection{The Second Question What Is Medical Ethics?}

Medicine among other fields of human activities needs to be regulated for its 
goal based and social nature. Moral and law are the main forms of social regulation. There are several fields of ethics connected to medical activities: medical ethics, clinical ethics, bioethics, environmental ethics. Scholars who regard ethics as the systematic and rigorous examination of moral norms tend to distinguish historically between medical ethics and medical morality. When they speak of the genre of medical ethics as it existed prior to the mid-twentieth century, they may label it medical morality. By this it was nothing more than principles of etiquette and decorum informed by commonly held morality and circumscribed by religion and law. To such scholars medical ethics is a quite recent development, at which there had been only rare, spasmodic, and largely unnoticed earlier attempts. Thus understood medical ethics, as a social and intellectual phenomenon, was initially but an adumbration of bioethics, of which it is now a subdivision [13]. Bioethics the word itself was coined in 1970 by the late oncologist Van Potter, who conceptualized bioethics as a comprehensive field of thought and action: biology combined with diverse humanistic knowledge forging a science that sets a system of medical and environmental priorities for acceptable survival [14]. According to Van Rensselaer Potter 1970: "bioethics" refers to the moral, social and political problems that arise from biology and the life sciences generally that involve, directly or indirectly, human wellbeing. Warren Reich in the revised edition of the encyclopedia of bioethics define bioethics as the systematic study of the moral dimensions-including moral vision, decisions, conduct and policies-of the life sciences and health care, employing a variety of ethical methodologies in an interdisciplinary setting [13]. According to Mappes and Zembaty, it is now possible to identify biomedical ethics as one branch of applied ethics (normative) ethics. The task of biomedical ethics is to resolve ethical problems associated with the practice of medicine and/or pursuit of medical research [11]. Medical ethics has several distinct but related references, it may designate therelationship between the general moral beliefs of a culture and the activities directed towards preserving health and healing the sick [9]. Medical ethics also referred to the rules of conduct that are established by formal bodies of medical profession in the course of regulating itself, such as the prohibition of the sexual exploitation of ones patients or it may refer to novel ethical dilemmas as they specifically confront doctors, such asthe appropriate point at which is partly to cease life sustaining measures for dying patients [15]. Thomasma define medical ethics as a field of study about moral problems created by modern practice of medicine [16]. Clinical ethics,which is partly an outgrowth of medical ethics, can refer either to uncontroversial codes of conduct that govern all clinicians, or to novel ethical dilemmas. Clinical ethics is the systematic identification, analysis, and resolution of ethical problems associated with the care of particular patients. Its goalsinclude protecting the rights and intrests of patients assisting clinicians in ethical-decision-making, and encouraging cooperative relationships among patients and those close to patients, clinicians and health care instituations [15]. 


\subsection{The Third Question Is What Are the Types of Ethical Approaches in Relation to the Medical Practice?}

There are two types of approaches in the ethics one is normative and the other one is non Normative which is divided into two subtypes metaethics and descriptive ethics [11].

\subsubsection{Normative Ethics}

It is a branch of philosophical or theological inquiry that set out to give answer to the Questions [12] which general moral norms form the guidance and evaluation of conduct should we accept and why? The ethical theories attempt to identify and justify these norms which are often called principles [13]. Normative ethics is clearly a practical discipline dealing with practical moral problems [10]. So it means the development of prescriptive theories of what sort of conduct is right or Wrong. Normative ethics is divided into: General and practical or applied normative ethics. In applied normative ethics as opposed to general normative ethics the task is to resolve particular moral problems-for example is abortion morally justifiable? also to used the norms in the course of deliberating about moral problems, practices and policies in professions, institutions, and government [17].

\subsubsection{Non Normative Ethics}

Is to establish what factually or conceptually is the case, not what ethically ought to be the case. There are two types of non-normative ethics descriptive ethics and metaethics [18], the descriptive ethics, which is simply an objective study of the ethics of some particular group or some set of ethical standards. It asks empirical questions such as how do people think they ought to act in this particular situation? How do people actually behave in this particular circumstance of ethical concern [13] so it uses scientific technique to study how people reason and act for example, anthropologist, sociologists and historians determine which moral norms and attitudes are expressed in professional practice, in professional codes, in institutional mission, statement and rules and public polices, they study phenomena such as surrogate decision making, treatment of dying and the nature of consent obtained from patients [17]. The second type is metaethics: Is the branch of philosophical or theological inquiry which involves analysis of the, language, concepts and methods of reasoning in normative ethics for example metaethics addresses the meaning $s$ of terms such as right, obligation, virtue, justification, morality and responsibility, it also concerned with moral epistemology (the theory of moral knowledge the logic and patterns of moral reasoning and justification, the possibility and nature of moral truth). So meta-ethics is the study of just what "ethics" means and to what degree ethical claims can ever be justified and how [13].

\section{Conclusion}

Through understanding the basics of the ethics, the awareness of the medical 
ethics in the health care can be increased.

\section{Conflicts of Interest}

The author declares no conflicts of interest regarding the publication of this paper.

\section{References}

[1] Medical Ethics. New World Encyclopedia. http://www.newworldencyclopedia.org/p/index.php?title=Medical_ethics\&oldid=10 $\underline{14490}$

[2] BMC Medical Ethics 2006.

[3] Førde, R. (2012) Cambridge Quarterly of Healthcare Ethics. Vol. 21, Cambridge University Press, Cambridge, 517-526.

[4] Kumar Babu, G. (2015) Importance of Ethics in Today's Society: Special Emphasis on Medical Ethics. RRJMHS, 4.

[5] (2011) Mayo Clinic Proceedings, Vol. 86, 421. https://www.mayoclinicproceedings.org/

[6] Khan, M.I. and Tameer, S. (2016) Medical Ethics: Understanding, Teaching and Practice. International Journal of Pathology, 14.

[7] Christian Health Care Ethics: A Users Guide: Solving Moral Dilemmas in Medicine for Providers and Patients.

https://rdmacaleer.wordpress.com/2015/01/25/heath-care-ethics-basics/

[8] Velasquez, et al. (1988) Ethics and Virtue. Issues in Ethics V1 N3.

[9] Becker, L. and Becker, C.B. (2001) Encyclopedia of Ethics. Routledge, London and New York.

[10] Garrett, T.A., Baillie, H.W. and Garrett, R.M. (2000) Health Care Ethics Principles and Problems. 4th Edition, Prentice Hall, Upper Saddle River.

[11] Mappes, T.A. and Zembaty, J. (1986) Biomedical Ethics and Ethical Theory Second Edition. McGraw-Hill Book Company, New York.

[12] Christine, H. (1995) Professional Ethics and Organizational Change in Education and Health. Edward Arnold, Great Britain.

[13] Sugarman, J. (2001) Methods in Medical Ethics. Georgetown University Press, Washington DC.

[14] Jennifer, R. (2005) Historicizing History, the Ethical Dilemma of East Asian Bioethics. Critical Asian Studies, 37, 2.

[15] Ahronheim, J.C., Morenom, J. and Zuckerman, C. (1994) Ethics in Clinical Practice. Evan R. Schnittman Laurie Anello, USA.

[16] Thomasma, D.C. (2003) Military Medical Ethics. Borden Institute, USA.

[17] Beauchamp, T.L. and Childress, J.F. (2009) Principles of Biomedical Ethics. 6th Edition, Oxford University Press, Oxford.

[18] https://medical-dictionary.thefreedictionary.com/nonnormative+ethics 